\title{
THE IMPORTANCE OF COMPETENCY MODEL DEVELOPMENT
}

\section{Aija Staškeviča*}

\begin{abstract}
Personal competencies are significant predictors of employee outcome. Nowadays, due to the rapid development of technologies and increased automation level, competency requirements have changed. Therefore, experts develop and make regular updates in the general competencies and in the specific competency models for each industry. In 2018, the European Commission developed the Council Recommendation on Key Competencies for Lifelong Learning, which defines the core competencies necessary to improve performance, to sustain current standards of living and to adapt to market changes. Competency models are particularly significant in order to produce innovations where the educational level and knowledge and the skills and attitude of employees are essential.

The purpose of the research is to define the basic concepts of actual competency models and to determine the advantages of their development. This research is a literature review for building a literature background for the next stage of the investigation, which will be empirical research.

The outputs of this research are four hypotheses on the influence of the practical application of competency models, including the use of competency models in the development and implementation of training programmes as a positive impact on learners' results and attitude. Use of general competency models does not ensure the implementation of fully-fledged competency-based training programmes in a specific area.

The literature review has identified that the major advantages of the development and use of competency models are improved performance and evaluation system optimisation. It is essential for each industry to identify its own competency requirements although there are still specific industries in which competency models have not yet been fully developed. It is concluded that most of the research evidence on competencies is, nevertheless, related to medium and large sized companies and industrial plants. Different approaches are required to analyse and develop competency models depending on the company size.
\end{abstract}

Keywords: competencies, competency model, employee development

JEL Classification: M12, J24

\section{Introduction}

According to the first principle of the European Pillar of Social Rights, "Everyone has the right to quality and inclusive education, training and life-long learning in order to maintain and acquire skills that enable them to participate fully in society and successfully manage transitions in the labour market". It also states that everyone has the right to timely and tailor-made assistance in order to improve employment or self-employment prospects. This includes the right to receive support for job searches, training and re-qualification

* University of Latvia, Faculty of Business, Management and Economics (aija.staskevica1@gmail.com). 
(EC, 2018). The competency approach can support the implementation of these conditions in life. This is why, in 2006, the European Parliament and the Council of the European Union adopted the Recommendation on Key Competencies for Lifelong Learning. Since its adoption, the recommendation has been the main reference for the development of competency-based education, training and learning. However, due to the rapid change in the external environment, the requirements for competencies also change rapidly. The work is more computerised, automated and robotised. Technological development has a significant impact on the required skills and knowledge. It affects both the business environment and everyday life. Based on the above, in May 2018, the European Commission developed the Council Recommendation on Key Competencies for Lifelong Learning defining the core competencies that are necessary to improve performance, to sustain current standards of living, to adapt to market changes and to support high rates of employment (CEU, 2018). In general, people need a set of appropriate and most relevant competencies to meet the changing demands of the labour market and the required standards. The development of competency models facilitates the solution to this issue.

The purpose of this research is to define the basic concepts of actual competency models and to determine the advantages of their development. This research is a literature review for building a literature background for the next stage of the investigation, which will be empirical research.

\section{Theoretical Framework}

The essence of competency will first be determined in order to understand the concept of competency models, the basic principles and the importance of their development as well as to define their advantages.

\subsection{Concept of Competency}

In 1973, McClelland (1973) published the study Testing for Competency rather than for Intelligence in which personal competency (defined as motives and personality traits) or individual characteristics were recognised as significant predictors of employee performance and success. The researcher's work was provocative because he claimed personal competencies to be a more important factor in predicting occupational success than traditional psychometrics, for instance, IQ and aptitude tests. McClelland (1973) is considered to be the founder of the competency theory in personnel management. Key competencies are often used to describe an organisation's competitive advantages. Boyatzis (1982) defined competency as the underlying characteristic of a person that resulted in an effective and/or better work performance. In 1990, Prahalad and Hamel introduced the characteristics of key competencies of an organisation for the first time (Prahalad and Hamel, 1990).

The word 'competency' comes from the Latin word 'competentia', which can be translated as 'is authorised to judge', respectively, 'a person who has the right to speak'. Skorková (2016) summarised various interpretations of the competency concept as follows:

- Competency as authority and responsibility. An employee has the right to take certain actions. Therefore, it refers to what was given to a person from the outside.

- Competency as a person's ability to perform certain activities - quality, skills and the ability to do something competently. 
There are several definitions of competencies. Mooney (2007) concluded that different competencies are skills, knowledge and abilities that are characteristic of being visible to customers and are better than those of their competitors and difficult to imitate. In a strategic implementation, these different competencies can lead to sustainable competitive advantages. Competencies can be defined as the mobilisation of knowledge, actions and emotions used to create value (Bendassolli et al., 2016). According to the United Nations Industrial Development Organisation, competency includes a combination of knowledge, skills and behaviour that are practised for self-improvement (UNIDO, 2002). Likewise, Salleh et al. (2015) determined that competency is a set of skills, knowledge and behaviour that characterises a person's better performance in each particular aspect. Competencies exist due to personal values in life, attitude and internal motivation for the quality performance of tasks and the creation of excellent work. Competencies are not only knowledge and skills; they are related to the ability to perform complex tasks in specific circumstances (in a special context). Competencies are a proven ability to responsibly and autonomously use one's knowledge, skills and abilities (personal, social and/or methodological) in different situations, for instance: work, study, professional and personal development (Chiru et al., 2012). This means that a competent person must be able to understand the circumstances and adapt to them depending on the situation.

According to the EU Council's terminology, competency is a compilation of knowledge, skills and attitudes where:

- Knowledge is the facts and figures, concepts, ideas and theories that have already been identified and support understanding of a specific field or topic.

- Skills are defined as the ability and capacity to carry out certain processes and use existing knowledge to achieve results.

- Attitude is described as the person's mindset and intention to act or react to an idea, persons or situation (CEU, 2018).

Another similar competency model has been developed, i.e. the Iceberg Competency Model (see Figure 1), which includes the components as follows:

- Skills

- Knowledge

- Attitude

- Interpersonal skills

- Motivation

- Achievement (Salleh et al., 2015)

\section{Figure 1 | Iceberg competency model}
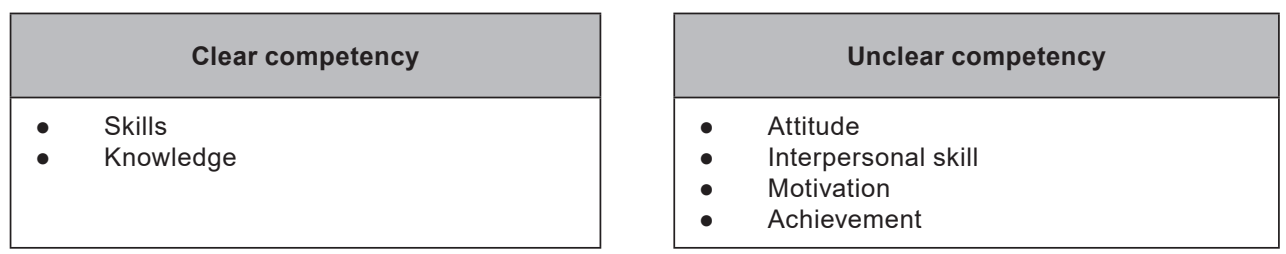

Source: (Salleh et al., 2015) 
Consequently, there are several competency definitions that are similar to each other although each organisation may have a different competency concept. To summarise, it can be said that the core competency components include knowledge, skills and abilities or attitudes.

\subsection{Competency Model Concept}

In the first development phase of the competency-based theory which lasted from the 1960s to the 1990s, the study and evaluation of competencies were focused on the observation of individual competencies. Competency was defined as a skill developed by selforganisation and required to perform the person's work. In the second phase, in the 1990s, personnel management was focused on the creation of competency models and their management in organisations. The third phase in personnel management, which continues today, is the typical identification of the core competencies required to gain a competitive advantage (Skorková, 2016).

The EU Council Recommendation for each person's core competencies includes:

- Literacy competency;

- Multilingual competency;

- Mathematical competency and competency in science, technology and engineering;

- Digital competency;

- Personal, social and learning to learn competency;

- Citizenship competency;

- Entrepreneurial competency;

- Cultural awareness and expression competency (CEU, 2018).

Everyone needs the key competencies referred to in the Council Recommendation in order to improve performance, meet modern living standards, adapt to market changes and be competitive in the labour market. Identification of competencies in society led to the so-called competency model, which is characteristic of a particular position. The group of key competencies forms a competency model. Therefore, the competency model describes a combination of specific knowledge, skills and other personal qualities required to effectively perform duties in an organisation. The model structure should support the use of competencies across the selected human resource functions. The competency model should give a clear definition of each competency, including measurable or observable performance indicators or standards. These will be used by the individuals who are the evaluators (Skorková, 2016).

There are two main competency model research directions. First, job-specific models are focused on the development of specific skills in specific workplaces. Examples of specific competencies include product knowledge, the administrative and technical fields of private company managers, and the training and qualification building skills for the training of specialists. Regardless of the specific competencies' characteristic for the jobs, there are some common core competencies such as entrepreneurial competencies (for instance, strategic management, innovation and change), selfexpression and interpersonal competencies as well as leadership competencies (Shum, Gatling and Shoemaker, 2018). Sisson and Adams (2013) have proved that general 
competencies account for $86 \%$ of all competencies. This is why the second competency research direction is focused on the development of general competency models. General models pay more attention to business, personal and management competencies and place less emphasis on technical skills.

\section{Advantages of Competency Model Elaboration and Competency Development}

A knowledge-based economy, fact memorisation and procedural knowledge are important but not sufficient factors for business success and progress. Such skills as problemsolving, critical thinking, the ability to cooperate, creativity, and self-regulation are much more relevant in today's fast-paced society than ever. These are the tools that provide the opportunity to work in real time, create new ideas, new theories, new products and new knowledge (CEU, 2018). Human competencies affect their behaviour, 'we do what we can' (Loots, Cnossen and Witteloostuijn, 2018). In addition, it has been proven that persons believing that they are good at doing some kind of task and derive pleasure from it, have a greater chance to persist in doing the task and improve their abilities even more. The person's perception that he or she is competent activates the said person's behaviour and ensures greater development in the particular field (Deci and Ryan, 2000). The development of employee skills is essential for the continuous improvement and adaptation of the workforce competencies.

Development of competency models has substantial advantages in different fields (see Figure 2). The author compared the academic field with the private business and public sectors because the goal of the academic field is to ensure competencies that will be useful for two other sectors and the main advantages vary depending on sector aims. Competency models are useful tools for teachers to identify and develop the knowledge, skills and abilities required for future leaders (Sisson and Adams, 2013; Shum, Gatling and Shoemaker, 2018). High-quality education, training and lifelong learning provide everyone with the opportunity to develop core competencies. Therefore, a competency-based approach can be used in all education, training and learning programmes regardless of the education level and age (The Council of the European Union, 2018). According to the findings of Chih et al. (2003), the analysis of content for competency in education and training is the essential factor in order to increase training effectiveness. It also includes the development of standards related to the identification of the competencies required.

Likewise, the development of competency models in companies allows identifying the required skills that would contribute to the development of the organisation. Competencybased management, in which competency models are the main tool in human resource systems and practices, is currently topical. Competency-based selection is effective in the rapidly changing business environment in which companies recognise the value of interpersonal relationships, effective communication, teamwork, willingness to support these changes, and the ability to learn quickly (Skorková, 2016). There is a considerable range of studies proving the relation between different competencies and a company's performance and between different competencies and competitive advantages (Fernandez et al., 2018). However, most of the evidence from these studies relates to medium and large sized companies and industrial plants (Miller, Dröge and Vickery, 1997; Fernandez et al., 2018). Small companies should constantly strive for a sustainable competitive advantage over their competitors. Competency models can be used in many 
human resources development areas, i.e. recruitment of officials, remuneration process, training, job performance management and the elaboration of a development programme. It is the main tool for employee assessment, career planning and talent management. It should be mentioned that the final list of competencies included in the competency model is sometimes a big surprise to the company who requested the model. It can reveal the difference between what is officially expected by the company (declaring it in its internal policy) and what is actually required from its employees (Skorková, 2016).

A person's individual competency is something typical of a person that can be used to predict the level of performance. It has been established that there is a correlation between the employees' competencies and their productivity (Buchel, 2002). Each individual's competency should be able to support the organisation's strategy and any changes made by management (Muizu and Yudomartono, 2016). A full assessment of the person is used in the competency-based selection process. The main task is to determine the person's potential and how this person can contribute to the survival of the organisation, quality of services, productivity, financial indicators and sustainable development (Bharwani and Jauhari, 2013; Blayney, 2009). Competency-based human resources management is regarded to be an effective means of people management in the private and public sectors (Skorková, 2016). Another advantage of competency development is that it is positively associated both with business performance and with the employees' professional beliefs and job satisfaction (Blayney, 2009; Ko, 2012).

Figure 2 | Main advantages of competency model development

\begin{tabular}{|c|l|}
\hline Academic field & $\begin{array}{l}\text { - Development of skills and abilities of students } \\
\text { - Improvement of quality and effectiveness of teaching }\end{array}$ \\
\hline - Process optimisation of the development of standards
\end{tabular}

Source: Author's own processing based on the literature review

There is numerous research in which entrepreneurial and management competencies were studied (Shum, Gatling and Shoemaker, 2018; Muizu and Yudomartono, 2016; Bendassolli et al., 2016; Boyatzis, 1982; Blayney, 2009). Greater attention is paid to management competencies since the quality of the management's work has a strong impact on the company's success. These competencies include technical skills, conceptual skills and human skills that support business development and management (Muiz and Hilmiana, 2016). Man (2001) defined six dimensions of entrepreneurial competency, including strategy, opportunity, relationships, conceptual, organisation and commitment. The importance of entrepreneurial competency is confirmed by empirical evidence. The major internal setback to entrepreneurship results from the emotional aspects 
(fear of responsibility, fear of risks and stress, lack of self-confidence), relationship aspects (lack of social networks), and the lack of significant leadership competency. Entrepreneurial traits are persistence, the ability to overcome problems and limited risk-taking as well as the ability to innovate and build social networks (Bendassolli et al., 2016).

Nevertheless, competencies must vary depending on the company's industry, and not all of the industries can boast of having a range of extensively researched competencies. For instance, in the context of creative industries and given the peculiarities of this context, studies on entrepreneurial competency and entrepreneurial personality are still limited (Bendassolli et al., 2016). At the same time, creative and entrepreneurial competencies are an essential precondition for the facilitation of competition and/or co-operation (Loots, Cnossen and Witteloostuijn, 2018). Improved quality and competency result in a significant improvement in productivity and the ability to produce competitive creative products. This is important since investments in human capital are not small, but results can often only be seen in the foreseeable future. And yet, literature provides several combinations of competency model research that facilitate the attempt to find the list of cognitive, emotional, moral and social competencies that would be better aligned with creative industries and help understand the factors most directly related to the successful performance of entrepreneurs in this work (Bendassolli et al., 2016).

In general, competency models are an effective tool for improving employee performance both in the public and private sectors. They are particularly important in the recruitment and training process; the development of competency models also contributes to sound decision-making.

\section{Results}

The literature studied has undeniably demonstrated that the use of the competency-based approach in academic and business sectors improves the results achieved. Therefore, the author of the research proposes the following hypothesis, which will be tested by an empirical study:

\section{H1: The use of competency models in the development and implementation of training} programmes has a positive impact on learners' outcomes and their attitude.

The literature review has shown that there are both general and specific competency models. Their development helps find suitable job performers and also provides the possibility to distinguish between a potentially average performer and a performer whose performance will be higher than the average. However, regardless of the fact that general competency models are important tools both for personnel selection and development of training programmes, they cannot be fully applied in each field. They need to be adapted depending on the activity type and company size. Based on this, the following hypothesis is raised:

H2: The use of general competency models does not ensure the full implementation of competency-based training programmes in the specific field.

According to the results, more and more attention is currently given to the knowledge of students and college students, their abilities, skills and behaviour. This occurs during 
the selection process and throughout the work and training process. One of the main goals of competency models is to facilitate the employer's experience in the evaluation process. Two hypotheses are put forward in this regard:

H3: Today, in the evaluation process, more attention is given to employee attitudes and skills rather than to their knowledge.

H4: In today's academic environment, more attention is paid to student attitudes and skills rather than to their knowledge.

Therefore, this research builds the literature background for the next stage of the investigation, which will be an empirical study. In general, the research resulted in four hypotheses on the importance of the practical use of competency models.

\section{Conclusions}

The research made it possible to draw the following conclusions:

1. Competency models are an effective tool for the development of employee performance both in the public and private sectors. Their use is particularly important in personnel selection, planning evaluation and training processes.

2. A wide range of research on the development of competency models is available in literature but there are still specific industries in which the required competencies are not extensively researched and competency models have not been fully developed.

3. General competency models form a larger part of the required competencies in a particular industry but are not sufficient for the fully-fledged use of the competency tool.

4. The competencies required depend on company size. Most of the competency research evidence applies to medium and large sized companies and industrial plants. Different approaches are required to analyse competency models and develop standards depending on the company size.

5. At present, competency-based theories are focused on the generalisation of competencies and the definition of key competencies in the market in general or in a particular industry.

6. Researchers are currently more focused on the exploration of direct management and entrepreneurial competencies and less focused on the competencies of low-level performers or the self-employed.

7. The major advantages of the development and use of competency models are improved performance, increased quality of training programme development, evaluation system optimisation, reasonable personnel recruitment and a more reliable prediction of their performance.

\section{References}

Bendassolli, P. F., Borges-Andrade, J. E., Gondim, S. M., \& Makhamed, Y. M. (2016). Performance, Self-Regulation, and Competencies of Entrepreneurs in Brazilian Creative Industries.

Psicologia: Teoria e Pesquisa, 32, pp. 1-9.

https://doi.org/10.1590/0102-3772e32ne221 
Bharwani, S., \& Jauhari, V. (2013). An Exploratory Study of Competencies Required to Co-Create Memorable Customer Experiences in the Hospitality Industry. International Journal of Contemporary Hospitality Management, 25(6), pp. 823-843. https://doi.org/10.1108/IJCHM-05-2012-0065

Blayney, C. (2009). Management Competencies: Are They Related to Hotel Performance? International Journal of Management and Marketing Research, 2(1), pp. 59-71

Boyatzis, R. E. (1982). The Competent Manager: A Model for Effective Performance. New York, NY: John Wiley \& Sons.

Buchel, F. (2002). The Effects of Overeducation on Productivity in Germany - The Firms' Viewpoint. Economics of Education Review, 21(3), pp. 263-275. https://doi.org/10.1016/S0272-7757(01)00020-6

Chih, Y. C., Wen, C. L., Fang, E. C., \& Yi, L. H. (2003). Construction of a Competency Analysis Model for Vocational High Schools. World Transactions on Engineering and Technology Education, 2(1), pp. 121-124

Chiru, C., Ciuchete, S. G., Lefter (Sztruten), G. G., \& Paduretu (Sandor), E. (2012). A Cross Country Study on University Graduates Key Competencies. An Employer's Perspective. Procedia Social and Behavioral Sciences, 46, pp. 4258-4262. https://doi.org/10.1016/j.sbspro.2012.06.237

Deci, E. L., \& Ryan, R. M. (2000). The "What" and "Why" of Goal Pursuits: Human Needs and the Self-Determination of Behavior. Psychological Inquiry, 11(4), pp. 227-268. https://doi.org/10.1207/S15327965PLI1104_01

EC (European Commission) (2018). European Pillar of Social Rights. [online] ec.europa.eu. Available at: https://ec.europa.eu/commission/sites/beta-political/files/social-summit-european-pillarsocial-rights-booklet_en.pdf [Accessed 5 Jan. 2018]. https://doi.org/10.2792/95934

Fernandez, A. I., Lara, P.R, Ugalde, M. C., \& Sisodia, G. S. (2018). Distinctive Competencies and Competency-Based Management in Regulated Sectors: A Methodological Proposal Applied to the Pharmaceutical Retail Sector in Spain. Journal of Retailing and Consumer Services, 42, pp. 29-36. https://doi.org/10.1016/j.jretconser.2018.01.007

Ko, W. H. (2012). The Relationships Among Professional Competence: Job Satisfaction and Career Development Confidence for Chefs in Taiwan. International Journal of Hospitality Management, 31(3), pp. 1004-1011. https://doi.org/10.1016/j.ijhm.2011.12.004

Loots, E., Cnossen, B., \& Witteloostuijn, A. (2018). Compete or Cooperate in the Creative Industries? A Quasi-Experimental Study with Dutch Cultural and Creative Entrepreneurs. International Journal of Arts Management, 20(2), pp. 20-31.

Man, T. W. Y. (2001). Entrepreneurial Competencies and the Performance of Small and Medium Enterprises in the Hong Kong Services Sector [doctoral dissertation]. The Hong Kong Polytechnic University.

McClelland, D. C. (1973). Testing for Competence Rather than for "Intelligence". The American Psychologist, 28(1), pp. 1-14. https://doi.org/10.1037/h0034092

Miller, D., Dröge, C., \& Vickery, S., (1997). The Impact of Performance on the Functional Favouritism of CEOs in Two Contexts. Journal of Management, 23(2), pp. 147-168. https://doi.org/10.1016/S0149-2063(97)90041-6

Mooney, A. (2007). Core Competence, Distinctive Competence, and Competitive Advantage: What Is the Difference? Journal of Education for Business, 83(2), pp. 110-115. https://doi.org/10.3200/JOEB.83.2.110-115 
Muizu, W. O. Z., \& Yudomartono, H. (2016). Competency Development of Culinary Creative Industries. Academy of Strategic Management Journal, 15(3), pp. 67-72

Prahalad, C. K., \& Hamel, G. (1990). The Core Competence of the Corporation. Harvard Business Review, 3, pp. 79-91.

Salleh, K. M., Khalid, N. H., Sulaiman, N. L., Mohamad, M. M., \& Sern, L. C. (2015). Competency of Adult Learners in Learning: Application of the Iceberg Competency Model. ProcediaSocial and Behavioral Sciences, 204, pp. 326-334.

https://doi.org/10.1016/j.sbspro.2015.08.160

Shum, C., Gatling, A., \& Shoemaker, S. (2018). A Model of Hospitality Leadership Competency for Frontline and Director Level Managers: Which Competencies Matter More? International Journal of Hospitality Management, 74, pp. 57-66. https://doi.org/10.1016/j.ijhm.2018.03.002

Sisson, L. G., \& Adams, A. R. (2013). Essential Hospitality Management Competencies:

The Importance of Soft Skills. Journal of Hospitality \& Tourism Education, 25(3), pp. 131-145. https://doi.org/10.1080/10963758.2013.826975

Skorková, Z. (2016). Competency Models in the Public Sector. Procedia - Social and Behavioral Sciences, 230, pp. 226-234. https://doi.org/10.1016/j.sbspro.2016.09.029

CEU (The Council of the European Union), (2018). Council Recommendation on Key Competences for Lifelong Learning. [online] ec.europa.eu. Available at:

https://eur-lex.europa.eu/legal-content/EN/TXT/?uri=uriserv\%3AOJ.C_.2018.189.01.0001. 01.ENG\&toc=OJ\%3AC\%3A2018\%3A189\%3ATOC [Accessed 13 Sep. 2018]

UNIDO (United Nations Industrial Development Organization), (2002). UNIDO Competencies: Strengthening Organizational Core Values and Managerial Capabilities. Vienna: UNIDO. 